\title{
Advances in X-ray Microtomography in SEM with Submicron Spatial Resolution: Applications in Life, Earth and Material Sciences
}

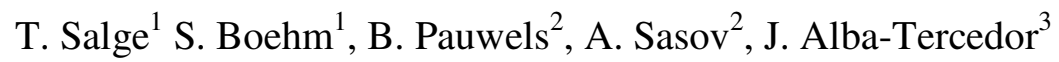 \\ 1. Bruker Nano GmbH, Schwarzschildstr.12, 12489 Berlin, Germany \\ 2. Bruker microCT, Kartuizersweg 3B, 2550 Kontich, Belgium \\ 3. Departamento de Zoologia, Facultad de Ciencias, Universidad de Granada, 18071-Granada, Spain
}

Scanning electron microscopy (SEM) is used to study the topology and chemical composition of the surface whereas micro-tomography (micro-CT) provides information on the internal microstructure of the sample. The micro-CT attachment for SEM allows to non-destructively image and measure 2D/3D morphometry throughout the entire volume on porous and/ or low density samples.

In Fig. 1, the objective lens of the SEM (1) focuses the electron beam (2) on a metal target (3). The SEM is switched to SPOT mode in order to produce X-rays at one position of the target. Part of the generated X-rays (4) pass through the object under investigation (5) that is installed on the rotation stage of the microscanner. A shadow X-ray image through the object is collected by a deeply cooled CCD detector (6), which is installed on the wall of the SEM specimen chamber and separated from the vacuum by a beryllium window. The images are digitized as 16 bit images of 512 by 512 pixels or 1024 by 1024 pixels. The magnification of the sample can be changed by adjusting the position of the sample in between the target and the camera. The resolution is $\sim 800 \mathrm{~nm}$, determined by the interaction volume of the electrons in the metal target. A brass target is used, generating mainly the characteristic X-rays of copper and zinc in the range between $8 \mathrm{keV}$ and $9.5 \mathrm{keV}$. Other materials such as titanium, silver or lead can be used as target material. In order to generate X-rays of high intensity, both accelerating voltage and beam current are set to their maximum values, respectively $30 \mathrm{kV}$ and $\sim 500 \mathrm{nA}$ (in our set-up: JEOL JSM-7000F, JEOL JSM-6490LV, FEI Quanta 400).

Various objects ranging in size from $\sim 100 \mu \mathrm{m}$ up to $1 \mathrm{~mm}$ were studied at high resolution regarding their external shape and internal structure. (1) Paleontology: Early Cretaceous radiolarian Pantanellium riedeli Pessagno, $150 \mu \mathrm{m}$ in size, was analyzed with a pixel size of $396 \mathrm{~nm}$. (Fig. 2a). (2) Zoology: $100 \mu \mathrm{m}$ sized eggs from two different orders of insects, the mayfly Ephemeroptera and human lice Anoplura [1], were studied with a pixel size of $510 \mathrm{~nm}$ (Fig. 2b). The increased spatial resolution provided by micro-CT attachment for SEM can display the internal structure and external attachments in high detail. It allows gender identification. (3) Mineralogy: A Pyroclastic deposit from the Yellowstone hotspot [2] was studied with a pixel size of $2.1 \mu \mathrm{m}$ (Fig. 3). Analysis of elongated vesicles in black vitrophyre provides insights in the viscosity and welding intensity at late-stage revesiculation of the welded rheomorphic ignimbrite. (4) Material sciences: The analysis on industrial materials e.g. glass filters, polymers, papers and composites (Fig. 5) is useful for quality control.

References:

[1] J Alba-Tercedor and I. Sanchez-Almazo, Bruker MicroCT Meeting, Hasselt, Belgium, (2013), pp.10.

[2] MJ Branney, B Bonnichsen, GDM Andrews, B Ellis, T Barry, and M McCurry, Bull Volcanol 70 (2008), p. 293-314.

[3] A Matsuoka (Niigata University) is acknowledged providing the radiolarian sample and MJ Branney (University of Leicester) for the ignimbrite sample. 


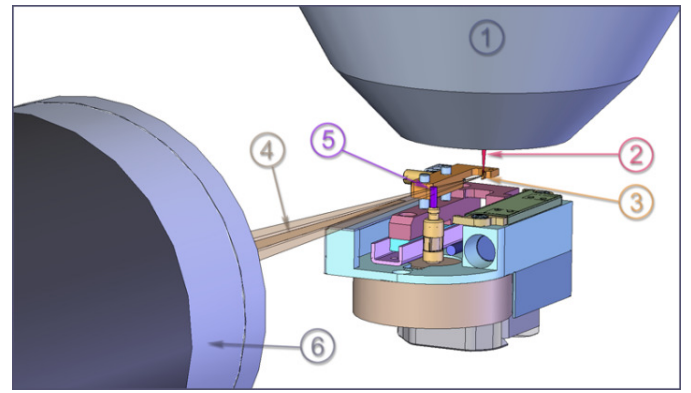

Figure 1. (a) Schematic drawing of the micro-CT attachment for a SEM.
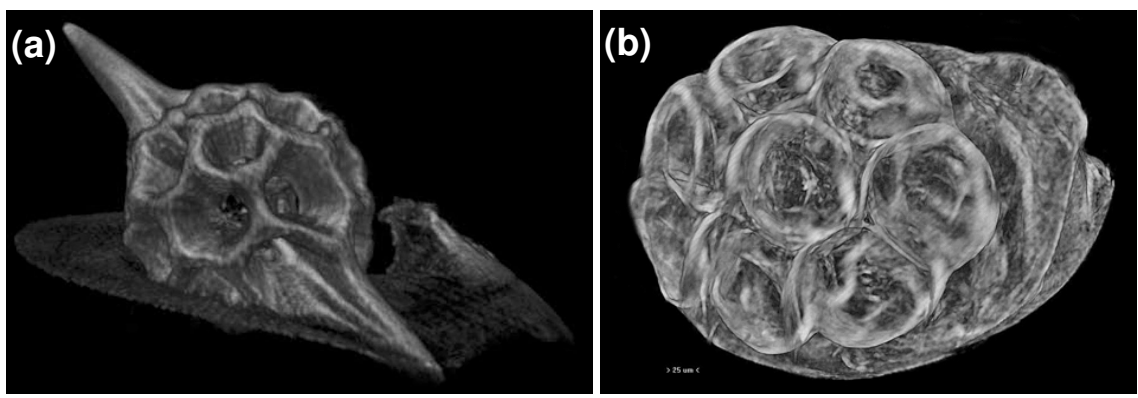

Figure. 2 Volume rendering reconstructions of (a) radiolarian Pantanellium riedeli Pessagno $(\sim 150 \mu \mathrm{m}$ in diameter) and (b) human lice egg Anoplura ( 100 $\mu \mathrm{m}$ in diameter).
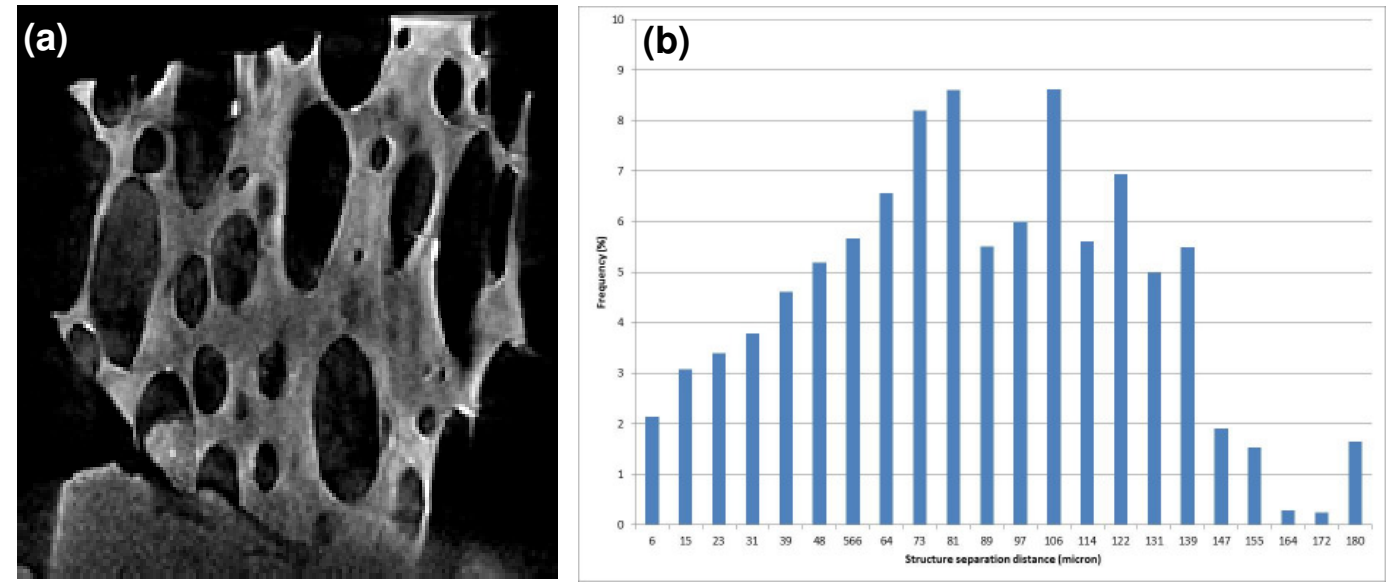

Figure 3. (a) Virtual slice of welded rheomorphic ignimbrite ( 1 $\mathrm{mm}$ in diameter). (b) Structure separation histogram which is indicative for vesicle size $(\mu \mathrm{m})$ in the sample of $\sim 50 \%$ porosity.
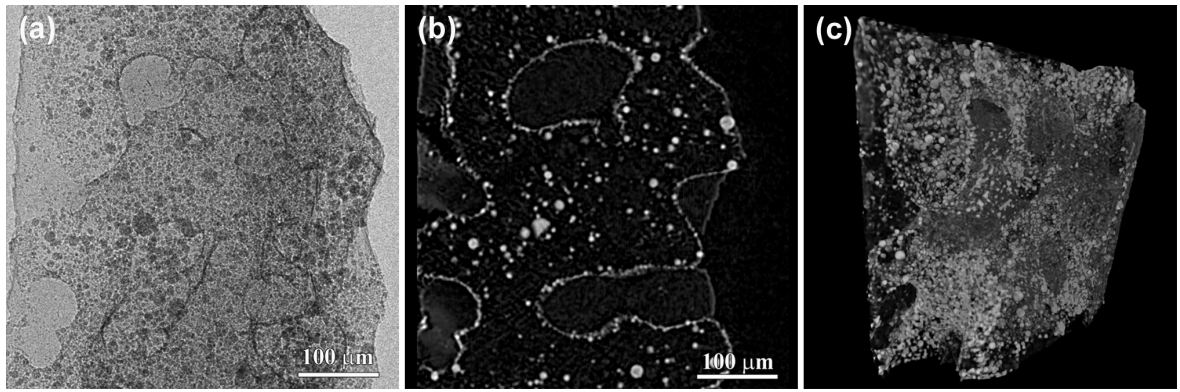

Figure 4. $\mathrm{PMMA} / \mathrm{PS}$ polymer with $\mathrm{Al}_{2} \mathrm{O}_{3}$ spheres. (a) X-ray projection image of the sample; (b) virtual coronal slice and (c) volume rendered 3D model. 